\title{
Design and Development of Recruitment and Assessment Information System using SMART Method
}

\author{
Retno Mumpuni ${ }^{1}$, Sugiarto, Kurnia Dwi Purna Prahara \\ Informatics Engineering \\ Universitas Pembangunan Nasional "Veteran" Jawa Timur \\ Surabaya, Indonesia \\ ${ }^{1}$ retnomumpuni.if@upnjatim.ac.id
}

\begin{abstract}
The rapid development of information technology, especially in the information systems area, has brought an easy to implement efficient work. Today, the most company still performs their business process manually, such as in conducting reseller search and assessing the performance of resellers tasks in which will get a reward from the company. From that problem, the company needs efficient reseller recruitment and rating information system to facilitate the company in searching for the new resellers and monitoring their performances. By applying the SMART (Simple Multi-Attribute Rating Technique) method, the proposed system can assist the company in assessing and determining which reseller may get the rewards. The SMART method itself has a criterion, and each of them has a weight value that will be used to perform its main task. From the result, we get that the proposed SMART-based system can provide the list of recommended resellers to get the rewards as an output.
\end{abstract}

Keywords-recruitment, assessment, information system, SMART method

\section{INTRODUCTION}

With the advancement of information technology, access to available information can take place quickly, efficiently, and accurately developments in the field of computers at this time have opened up opportunities as broad as possible to decision makers for those engaged in economics, government, science and so on to solve all problems with using a computer.

Most companies still conduct their business in manuals, such as looking for a new reseller and assessing their performance. However, executing those two tasks are not straightforward problems. Constraints are often encountered when the amount of reseller data is considerably large, and there exist many attributes or parameters that must be measured to determine the grade. In some cases, these problems can be addressed by utilizing proper data structures and multi-dimensional data processing methods.

To overcome these problems, companies need an information system [1] to facilitate their needs in finding the new resellers and monitoring their performance. In this work, we propose a reseller recruitment system and reseller assessment by employing the SMART (Simple Multi-Attribute Rating Technique) method [2][3].
Previously, there exist some works that employ SMART method to deal with their problems. In [4], the authors employ SMART to finish the measure selection problem. Further, SMART is utilized to support the existing measurement framework in the decision-making process. The authors in [5] further-utilizes SMART method to finish the task of multicriteria decision making, both in multi-objective and multicriteria cases. In [6], Edwards et al. Propose two approximation-based methods to measure the utility over multi attributes, called SMARTS and SMARTER.

Moreover, in [7], Zanakis et al. Provide a literature review of multi-attribute decision-making problems. The study over multi-criteria decision-making methods then further discussed by Velasquez and Hester in [8].

Finally, with this SMART-based proposed system, it will be straightforward to do reseller search and assessment of each reseller and reduce time and effort compared to the naïve approach. Moreover, we will focus mainly on building the information system that employs the SMART method to deal with.

\section{Methodology}

\section{A. SMART Method}

As for the calculation of the principal value in determining the recruitment and assessment of reseller performance, the system will use the SMART method. Simple Multi-Attribute Rating Technique (SMART), according to the [2][3], is a method for multi-attribute decision making. This multiattribute decision-making technique is used to support decision-makers in choosing several alternatives. Every decision maker must have an alternative that is by the objectives formulated. Each alternative consists of a set of attributes, and each attribute has values. This value is averaged on an individual scale. Each attribute has a weight that describes how important an attribute is compared to other attributes. This weighting and ranking are used to assess each alternative to obtain the best alternative. 'The models used in SMART are:

$$
u\left(a_{i}\right)=\sum_{j-1}^{m} w_{j} u_{i}\left(a_{i}\right) i=1,2, \ldots n
$$


where $w_{j}$ is the value of the criteria weighting and $u\left(a_{i}\right)$ is the criteria value of i-th utility.

Moreover, the techniques in the SMART method are:

- Determine the number of criteria

- Determine the percentage of the criteria weighting. The weight given to each criterion is carried out according to the ranking that is assessed based on the priority level. Usually formed with the statement "Criteria 1 is more important than criterion 2, which is more important than criterion $3 "$ and continues until the criteria $n$ are written, then normalized using formula as follows:

$$
\text { Normalization }=\frac{w_{j}}{\sum w_{j}}
$$

where $\mathrm{w}_{\mathrm{j}}$ is the value of the criteria weighting and $\Sigma \mathrm{w}_{\mathrm{j}}$ is the total number of weights of all criteria

- Provide the criteria for each alternative.

- Calculate the utility value for each sub-criterion

$$
u_{i}\left(a_{i}\right)=100 \% \frac{c_{\max }-c_{\text {out }} i}{c_{\max }-c_{\min }}
$$

where $u_{i}\left(a_{i}\right)$ is the $i$-th utility criteria value, $c_{\max }$ is the maximum criteria value, $c_{\min }$ is the minimum criteria value and $c_{\text {out }} i$ is the $n$-th criteria value

- Calculate the final value of each by using the formula from the SMART method.

$$
u\left(a_{i}\right)=\sum_{j-1}^{m} w_{j} u_{i}\left(a_{i}\right) i=1,2, \ldots n
$$

Table I provides the example of the computation to measure whether we may provide a reward for the reseller. Given that if the final utility value is above or equal to $51 \%$, then that reseller is feasible enough to get a reward. However, for below $51 \%$, that reseller may not get any reward. Table 1 describes the normalization formula for a reseller, as an example

TABLE I. AN EXAMPLE FOR NORMALIZATION COMPUTATION

\begin{tabular}{|c|l|c|c|}
\hline Code & \multicolumn{1}{|c|}{ Criterion } & $\begin{array}{c}\text { Weighing } \\
\left(\mathrm{w}_{\mathrm{j}}\right)\end{array}$ & $\begin{array}{c}\text { Formula: } \\
\text { equation } 3\end{array}$ \\
\hline A & Number of selling & $45 \%$ & 0.45 \\
\hline B & Location & $25 \%$ & 0.25 \\
\hline C & Number of stocks & $20 \%$ & 0.2 \\
\hline D & Working hours & $10 \%$ & 0.1 \\
\hline & $\sum \mathrm{w}_{\mathrm{j}}=100 \%$ & \\
\hline
\end{tabular}

After the normalization finished, then we can compute the utility value of each defined criteria. Table II describes the example of utility formula computation.

\section{TABLE II. AN EXAMPLE OF UTILITY VALUE COMPUTATION}

\begin{tabular}{|c|c|c|}
\hline Code & Formula: equation 3 & Result \\
\hline A & $100 \% \frac{100-45}{100-25}$ & 0.733 \\
\hline B & $100 \% \frac{65-25}{65-30}$ & 1.1428 \\
\hline C & $100 \% \frac{60-20}{60-30}$ & 1.33 \\
\hline D & $100 \% \frac{100-45}{100-25}$ & 1.25 \\
\hline
\end{tabular}

Shortly after normalization and utility value are obtained, then we may compute the final formula by using Equation 4, we obtain the following result:

Criteria A : Utility Value $25 \times 0.45 \times 0.733=8.24625$

Criteria B : Utility Value $65 \times 0.25 \times 1.1428=18.5705$

Criteria C : Utility Value $60 \times 0.2 \times 1.33=15.96$

Criteria D : Utility Value $60 \times 0.1 \times 1.25=7.5$

Final value $=8.24625+18.5705+15.96+7.5=50.27675 \%$

From the final value, since it is below $51 \%$, then we may conclude that this reseller is not feasible to get the reward from the company.

\section{B. System Development}

The main flowchart that describes the flow of reseller recruitment information system is figured in Fig. 1. The development of the proposed information system is based on an agile method [9]. 


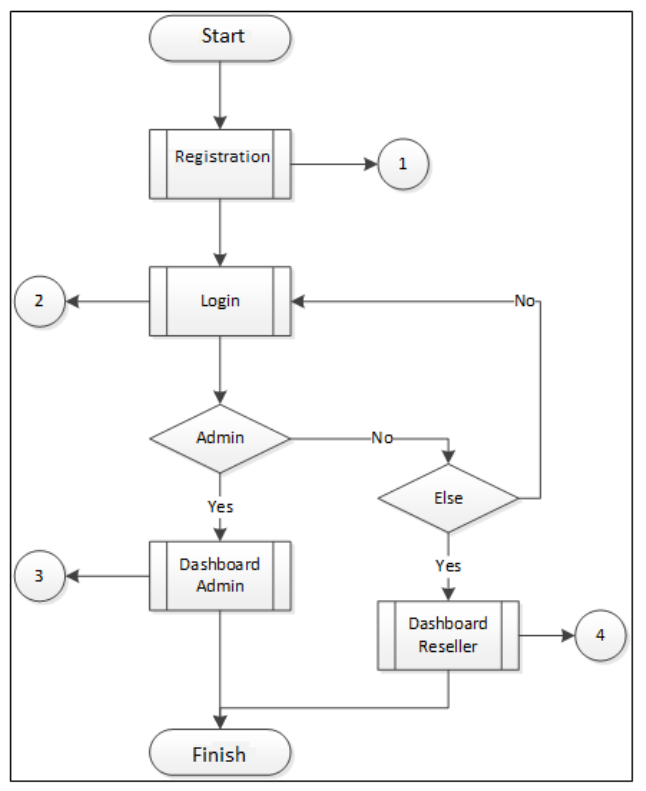

Fig. 1. The main flowchart

Further, for the flow of the computation of utility is figured in Fig. 2. We can see that the final decision is about whether we need to provide a reward or not.

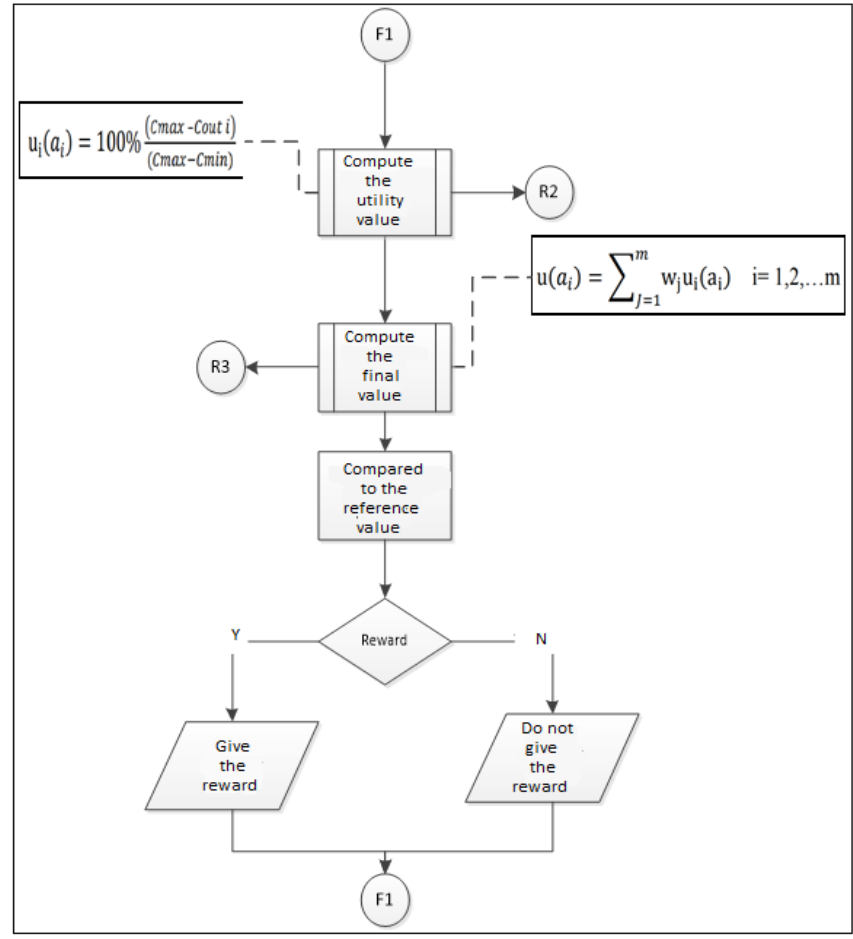

Fig. 2. The flowchart of the computation of utility value

Fig. 2 describes that in the final statement, our proposed system will compute the final result of the SMART method to be compared with the reference value. The final decision is the feasibility of a reseller in obtaining the reward.
Moreover, there exist use cases for several users. Fig. 3 depicts several use cases for the agent and the reseller.

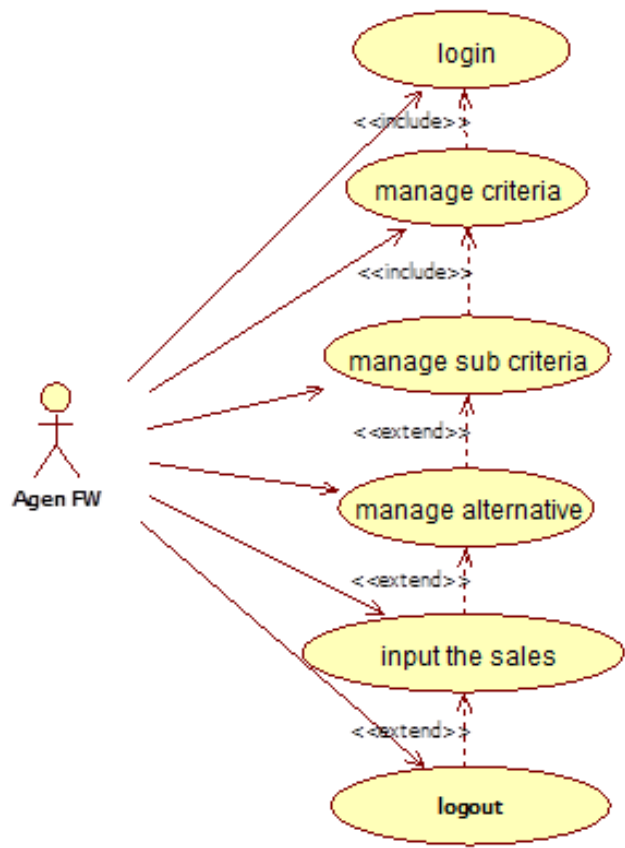

Fig. 3. Use Case Diagram for Agent

As in Fig. 3, there exist some use cases for the agent use. The first one is the login part to facilitate the agent user in entering the system. The second and the third use cases are managing the criterion and the sub-criterion. For the fourth part, our system defines the task of managing the alternative as the use case.

Finally, input the sales and logout become the last two use cases for the agent. As described previously, the role of an agent in our proposed system is supplying the goods to each reseller.

Moreover, there exist also some use cases for reseller user in our proposed system. As illustrated in Figure 4, there exist five use cases for the reseller user. The first one is registration, to facilitate a new user for signing up to the system. The second and third use cases are login and managing the profile for the reseller user. The purchasing data is the fourth use case, which is the main use case for a reseller. This part is mainly facilitating reseller user to deliver their main information, the sales. Finally, manage the password becomes the final use case for the reseller agent. 


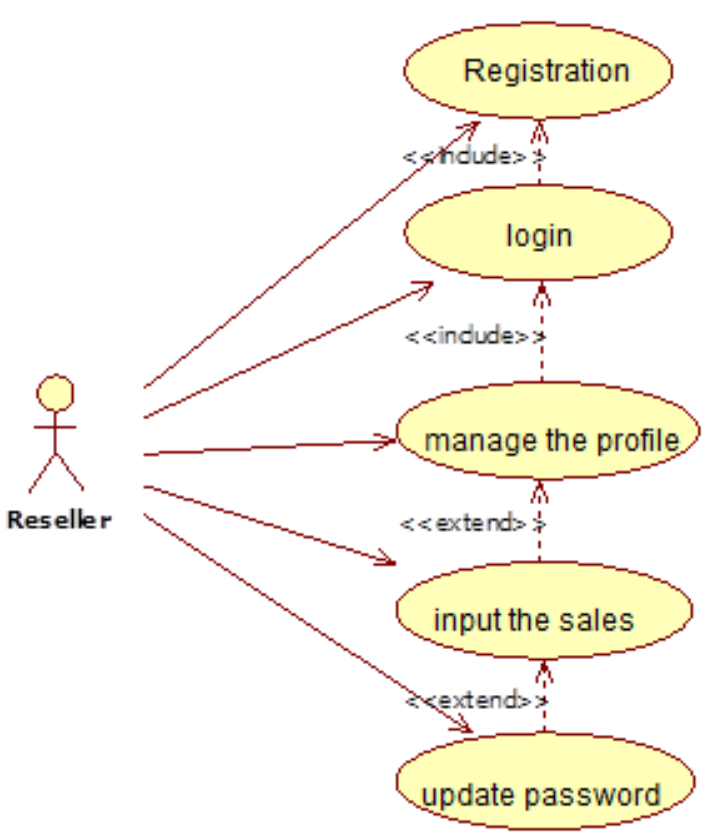

Fig. 4. Use Case Diagram for Reseller

\section{RESUlT AND DISCUSSION}

The proposed system is then implemented using PHP language on CodeIgniter framework [10]. It also employs MySQL [11] to facilitate the database management system. Since there exist numbers of form and use case in the system, we will only describe some main pages of our proposed system. For example, Figure 5 draws the home menu of the implemented system. In this figure, we get that there exists the logo of the company.

Moreover, Fig. 6 figures the dashboard for the administrator. Fig. 6 illustrates the movement of the goods sales chart that was successfully carried out by all resellers.

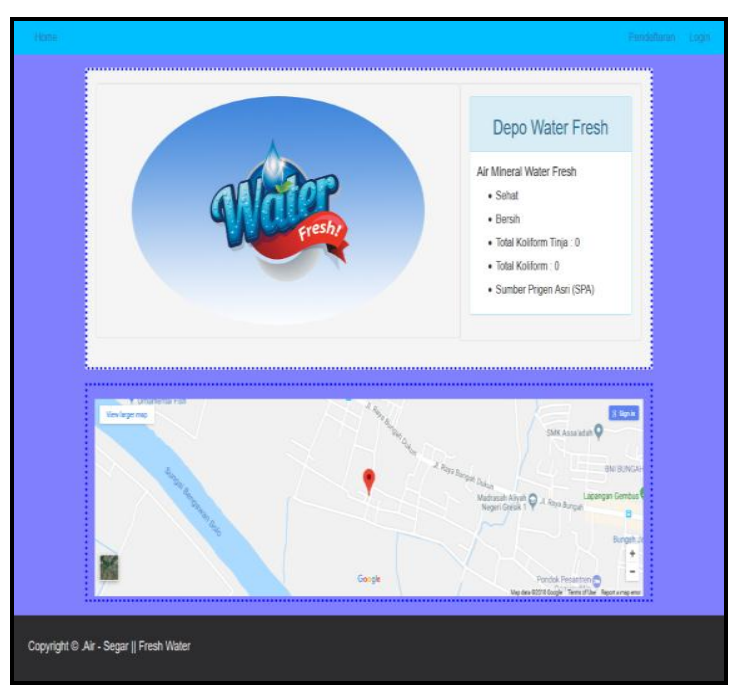

Fig. 5. The home menu of the proposed system

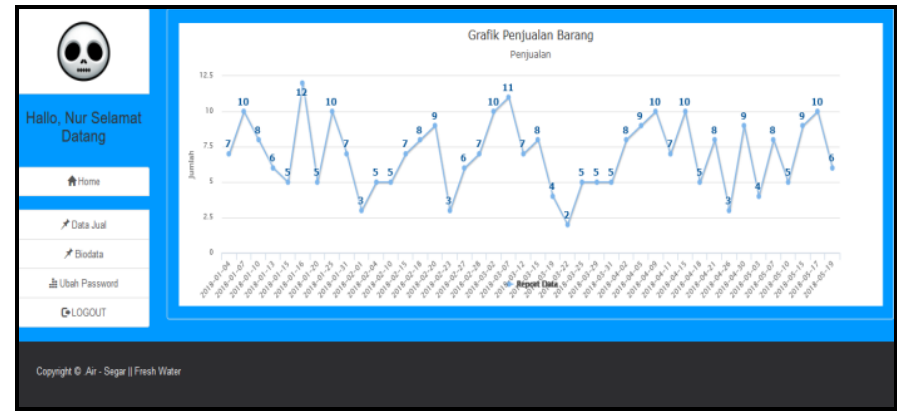

Fig. 6. The dashboard for administrator

Finally, Fig. 7 depicts the list of the rank over resellers according to its final value that based on the SMART method. We get that all three data-fulfilled resellers do not get the reward since their SMART utility final values are below $51 \%$.

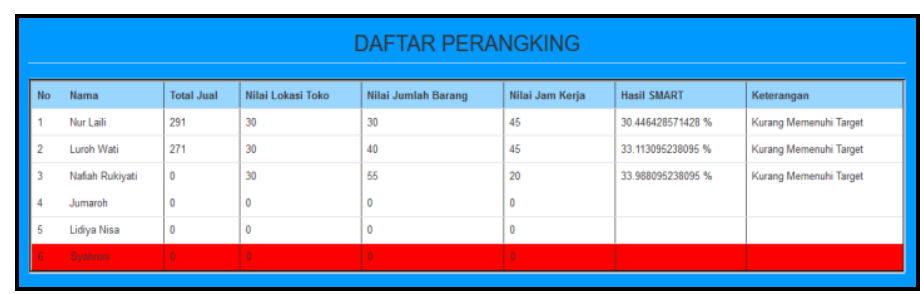

Fig. 7. The list of the rank based on the final value according to SMART method

\section{CONCLUSION}

The proposed information system to facilitate the recruitment and assessment of reseller has been successfully developed. The applied Cod Igniter framework provides a convenient development environment during the implementation phase. It is in line with the waterfall method and facilitates the developer to implement the code according to the planned stories. The information system meets all requirement in which to provide the list of the rank of resellers according to their SMART utility final value. The system is proven to be able to rank appropriately against into all resellers to provide valuable input for decision makers.

\section{REFERENCES}

[1] K. C. Laudon, J. P. Laudon, "Management Information System: Managing the Digital Firm", Pearson Education, 2015.

[2] W. Edwards, "Social Utilities". Summer Symposium Series, 6, Engineering Economist. 1971.

[3] D.L Olson., "Smart. In: Decision Aids for Selection Problems" Springer Series in Operations Research. Springer, 1996.

[4] G. Valiris, P. Chytas, M. Glykas, "Making decisions using the balanced scorecard and the simple multi-attribute rating technique", Performance Measurement and Metrics, Vol. 6 Issue: 3, pp. 159-171, 2005.

[5] D. Siregar, D. Arisandi, A. Usman, D. Irwan,R. Rahim, "Research of Simple Multi-Attribute Rating Technique for Decision Support", Journal of Physics: Conference Series, Vol. 930, 2017.

[6] Edwards, Ward, Barron, F. Hutton, "SMARTS and SMARTER: Improved Simple Methods for Multiattribute Utility Measurement", Organizational Behavior and Human Decision Processes, Vol. 60, Issue 3, pp. 306-325, 1994. 
[7] S. H. Zanakis, A. Solomon, N. Wishart, S. Dublish, "Multi-attribute decision making: A simulation comparison of select methods", European Journal of Operational Research, Vol. 107 Issue 3, pp. 507-529, 1998.

[8] M. Velasquez and P. T. Hester, "An Analysis of Multi-Criteria Decision Making Methods", International Journal of Operations Research Vol. 10, No. 2, pp. 56-66, 2013.
[9] D. Leffingwell, "Scaling Software Agility: Best Practices for Large Enterprices", Pearson Education, 2007.

[10] D. Upton. "CodeIgniter for Rapid PHP Application Development", Packt Publishing Ltd, 2007.

[11] S.M.M. Tahagoghi, H.E. Williams. "Learning MySQL: Get a Handle on Your Data”, O’Reilly Media, Inc., 2006. 